\title{
FIRST RESULTS FROM AUTOMATED MOTION AND STREAM MEASUREMENTS FROM FELS AND BLACK RAPIDS GLACIERS, ALASKA,

\author{
U.S.A.
}

(Abstract)

by

William D. Harrison,

(Geophysical Institute, University of Alaska, Fairbanks, AK 99775-0800, U.S.A.)

Charles F. Raymond,

(Geophysics Program AK-50, University of Washington, Seattle, WA 98195, U.S.A.)

Matthew Sturm,

(Geophysical Institute, University of Alaska, Fairbanks, AK 99775-0800, U.S.A., and

U.S. Army Cold Regions Research and Engineering Laboratory, Building 4070, Fort Wainwright, Fairbanks, AK 99703-7860, U.S.A.)

Keith Echelmeyer,

(Geophysical Institute, University of Alaska, Fairbanks, AK 99775-0800, U.S.A.)

and

Neil F. Humphrey

(Geophysics Program AK-50, University of Washington, Seattle, WA 98195, and

Division of Geological and Planetary Sciences, California Institute of Technology, Pasadena, CA 91125, U.S.A.)

The seasonal and shorter-period variation in the motion of a glacier and its relation to stream discharge provide information about the internal plumbing of a glacier, but the acquisition of year-round data with fine time resolution has not been achieved so far. We are developing automated techniques to measure velocity, strain, and seismicity year-round, and to measure stream-discharge characteristics in summer. Velocity is measured over $1 \mathrm{~d}$ intervals by automatic photography with control and finer spatial resolution provided by periodic optical surveys. Photography is also used to monitor lake and pot-hole drainings, and stream behavior. The vertical component of surface strain is measured with wire strain meters, usually at a resolution of 2 parts in $10^{6}$, at intervals of $1 \mathrm{~h}$ or less; average seismicity over the same interval is also measured. Stream stage is monitored by sonic ranger, and water turbidity, electrical conductivity, and temperature are monitored by instruments on board a small floating platform tethered in the stream.

Measurements on Fels and Black Rapids Glaciers in the central Alaska Range began in 1986. Some of the notable preliminary results are: much smaller surface vertical strain-rates than are accounted for by simple plane-strain models, evidence for discrete or inhomogeneous motion in the ice, seasonal variations in speed that are quite different on the two glaciers, short-period motion events lasting several days or less, diurnal variations in strain-rate and seismicity, sometimes modulating the short-period events, events that are simultaneous on both glaciers, and correlation between some motion events and stream turbidity and electrical conductivity. 